Article

\title{
Design of the Blade under Low Flow Velocity for Horizontal Axis Tidal Current Turbine
}

\author{
Jun-Hua Chen ${ }^{1, *}$, Xian-Cheng Wang ${ }^{1}$, Hao Li ${ }^{1, *}$, Chu-Hua Jiang ${ }^{2}$ and Ling-Jie Bao ${ }^{2}$ \\ 1 College of Science and Technology, Ningbo University, Ningbo 315300, China; wangxiancheng@nbu.edu.cn \\ 2 Faculty of Mechanical Engineering \& Mechanics, Ningbo University, Ningbo 315000, China; \\ jiangchuhua@nbu.edu.cn (C.-H.J.); baolingjie163@163.com (L.-J.B.) \\ * Correspondence: cjh@nit.net.cn (J.-H.C.); lihao1@nbu.edu.cn (H.L.)
}

Received: 9 November 2020; Accepted: 24 November 2020; Published: 4 December 2020

check for updates

\begin{abstract}
The blade is the key component for energy capture in horizontal axis tidal current turbine, and the blade's design is directly related to the efficiency of the power generation device. The seawater flow velocity is a crucial parameter for blade design. Since the seawater velocity changes constantly, it is extremely important to determine the design velocity of the blade. This article proposes a calculation method for the design velocity of the blade so that the designed blade can achieve better energy collection efficiency under a variable flow velocity. This study performed the following investigations: (1) The author tested and analyzed the seawater velocity variation at the experimental site, determining the designed flow velocity via calculations; (2) The author combined the blade element momentum and Wilson's optimization design method using the MATLAB software to calculate the blade shape parameters and predict the performance under a number of different flow velocity forecasts; (3) When testing the device under sea conditions, the experimental results showed that the performance capture devices and digital projections are basically the same, which verifies the validity and effectiveness of the design method.
\end{abstract}

Keywords: tidal current turbine; design velocity; blade element momentum theory; MATLAB

\section{Introduction}

There are numerous islands in China; therefore, tidal current energy resources are relatively abundant. Thus, the use of tidal current energy to generate electricity will greatly alleviate China's energy pressure and solve the problem of island power supply, which has an important economic and strategic significance.

The key component of tidal current turbine is the blade. The two most common forms are the vertical axis blades and the horizontal axis blades. Other countries such as France, the UK, the US, and Canada have already carried out relevant researches, and their studies in this field now focus on megawatt energy scales. China, however, began its research relatively late, as systematic research on tidal energy began only in 1982. To date, Harbin Engineering University, Northeast Normal University (NENU), and Zhejiang University have successfully developed high-power tidal current turbines [1]. Furthermore, many experiments have proven that horizontal axis blades offer greater efficiency and self-start performance in power generation than vertical axis blades.

There are many low-velocity watercourses in China. According to the "China Coastal Rural Marine Energy Resources Regionalization", among the 130 waterways along the coast of China, $70 \%$ have an average seawater velocity of about $1.5 \mathrm{~m} / \mathrm{s}$ [1]. However, most of the current energy capture devices have a high design flow velocity, and the rated power can only be output above $2 \mathrm{~m} / \mathrm{s}$ [2]. When working in a low flow rate environment, the blade tip-speed ratio is no longer the best, as the energy capture efficiency of the blade will be significantly reduced. 
Based on the blade element momentum, this article proposes a calculation method for the design flow velocity of the blade and adopts the optimization method to design the horizontal axis turbine under low flow velocity. The author used the MATLAB software to analyze and calculate the geometric parameters of the blades and predict the performance under different flow velocities.

\section{The Design Flow Velocity of the Blade}

Tidal current turbines are usually generated from the cut-in flow velocity to overcome the efficiency loss of the transmission system and then generate effective power. Before reaching the rated flow velocity, the power increases as the flow velocity increases, and the power remains basically unchanged between the rated flow velocity and the cut-out flow velocity. If the flow velocity exceeded the cut-off, the blade stalls, and the power drops. The most important factor in this process is to select an appropriate rated flow velocity, as this value restricts and affects the other parameters.

Seawater velocity changes periodically and constantly. At present, there is no suitable method to select the design flow velocity of a blade for designing a tidal current turbine. Some people choose the highest seawater velocity during high tide, and others choose an average seawater velocity. However, based on the blade element theory, we know that changing the seawater velocity directly influences the inflow angle, and the blade diameter, chord length, and twist angle are all related to the inflow angle. Therefore, choosing different designed flow velocities will produce different blade forms.

Figure 1 illustrates the experimental site of the horizontal axis tidal current power generation device. In the field test of the tidal current velocity in the sea area, it was found that the tidal current cycle is about $12.42 \mathrm{~h}$, with a regular half-diurnal tide. This means that, during a lunar day (about $1490 \mathrm{~min}$ ), there are two high tides and two low tides. The tidal range from high to low tide and from low to high tide is almost equal; the maximum flow velocity of the high tide is about $2.2 \mathrm{~m} / \mathrm{s}$, and the maximum flow velocity of the neap tide is about $0.5 \mathrm{~m} / \mathrm{s}$.

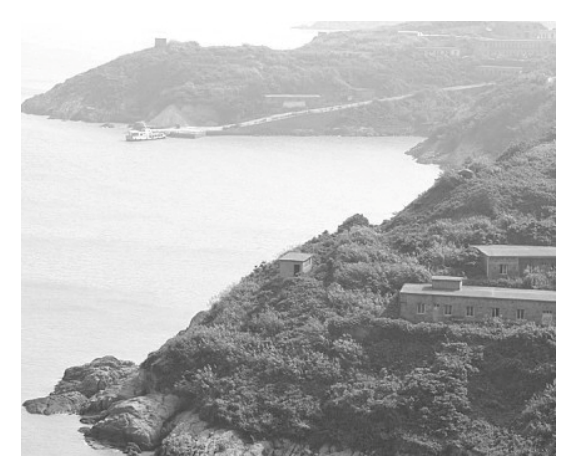

Figure 1. Test site in Yushan Island.

Through an analysis of the measured velocity data fitting, the author established the following mathematical model [3]:

$$
V(t)=V_{m} \sin \left(\frac{2 \pi}{T} t\right)
$$

where $V_{m}$ is the maximum flow velocity amplitude of the tidal current, and $T$ is the tidal cycle.

Since the tide at this experimental site is a reciprocating flow (i.e., the flow direction is opposite during fluctuations, and the fixed-pitch tidal energy generating device can only accept a unidirectional flow), the energy capture device captures the kinetic energy of the tide during the effective working time in a day as:

$$
\frac{1}{2} \rho s V_{r} T_{S} C_{p}=2 C_{p} \int_{t_{\text {in }}}^{t_{\text {out }}} \frac{1}{2} \rho s V_{m}^{3} \sin ^{3}(\omega t) d t
$$


where $\rho$ is the sea-water density $\left(1025 \mathrm{~kg} / \mathrm{m}^{3}\right), s$ is the blade swept area $\left(\mathrm{m}^{2}\right), \omega$ is the angular frequency of the flow velocity, $\omega=2 \pi / T, V_{r}$ is the rated flow rate, $C_{p}$ is the power coefficient, $t_{i n}$ is the cut-in flow velocity, $t_{\text {out }}$ is the cut-out flow velocity, and $T_{S}$ is the effective working time of the turbine, $T_{s}=2\left(t_{\text {out }}-t_{\text {in }}\right)$.

Through the integral calculation of Equation (2), $V_{r}$ can be expressed as follows:

$$
V_{r}=V_{m} \sqrt[3]{\frac{\cos ^{3}\left(\omega t_{\text {out }}\right)-\cos ^{3}\left(\omega t_{\text {in }}\right)-3\left[\cos \left(\omega t_{\text {out }}\right)-\cos \left(\omega t_{\text {in }}\right)\right]}{3 \omega\left(t_{\text {out }}-t_{\text {in }}\right)^{3}}}
$$

In a 1.5-month cycle, the maximum flow rate of sea water is different every day. At this experimental site, the astronomical tide occurred on the third and seventeenth day of the lunar calendar month, and the flow rate of the sea water on these two days was also the highest in the month. Since the cut-in velocity of the blade is difficult to predict at the beginning of the design, it will be affected by the entire tidal current power generation device. In this calculation, the cut-in velocity of the blade is ideally considered as zero; then, the velocity data tested in the half-moon cycle is substituted into Equation (2) to calculate the daily rated flow velocity of the half-moon period. Finally, the average value is taken as the design flow velocity of the blade.

We found that an effective working time for the blade is about nine hours or less in a day and about $135 \mathrm{~h}$ in a month cycle, which means that the blades are continuously working for only one-third of the time. Meanwhile on these days, the marine velocity continues to constantly change. In response to the above situation, the domestic Zhejiang University and Ocean University of China [4] developed variable pitch blades to be used not only to improve the self-starting performance of the blades, but also when the rated flow velocity is exceeded. The pitch can be used to limit the power output of the blade to protect the blade from being damaged by strong currents. However, the mechanism of the variable pitch blade is complicated, and its cost is higher than that of a fixed pitch blade. The harsh and ever-changing marine environment also makes maintenance difficult. Therefore, based on a comprehensive consideration, a fixed pitch blade was selected for this test at low flow rates.

\section{The Shape Design of the Blade}

\subsection{Blade Element Momentum Theory}

The blade element momentum theory is composed of blade element theory and momentum theory. The momentum theory considers an idealized model of blade design, but in actual work, there is energy loss; thus, to improve the theory's accuracy, Wilson proposed integrating the loss factor into this theory. Using momentum theory, the force $(d F)$ acting on the blade element of width and the torque $(d T)$ can be represented as below [5]:

$$
\begin{gathered}
d F=F 4 \pi \rho V_{1}^{2} a(1-a) r d r \\
d T=F 4 \pi \rho V_{1} \Omega b(1-b) r^{3} d r
\end{gathered}
$$

where $V_{1}$ is the sea velocity far up stream, $a$ is the axial induction factor, $b$ is the tangential induction factor, $\Omega$ is the angular velocity of blades, and $d r$ is the blade element of width.

In blade element theory, blades can be divided infinitesimally along the wingspan. Figure 2 shows the force analysis situation of the blade element. 


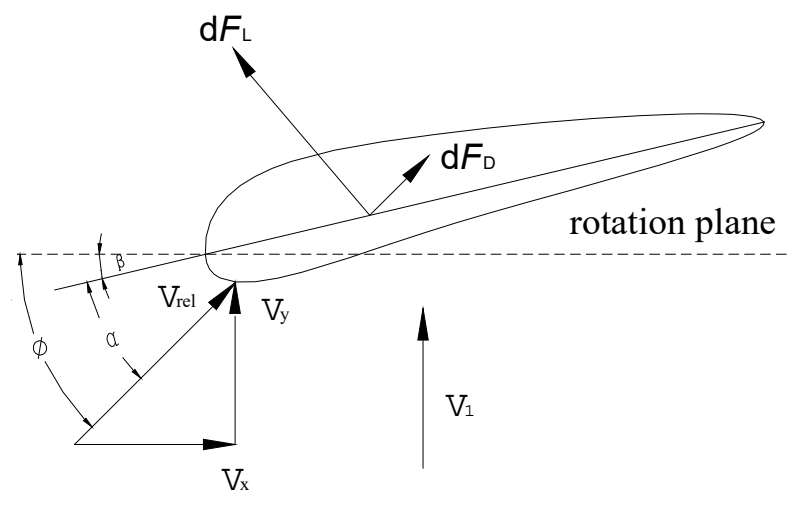

Figure 2. Force analysis of the blade.

The resulting flow velocity relative to the blade element $V_{\text {rel }}$ and the inflow angle $\phi$ are represented as below [6]:

$$
\begin{gathered}
V_{r e l}=V_{1}(1-a) / \sin \phi \\
\phi=\beta+\alpha=\arctan \left[\frac{(1-a) V}{(1+b) \Omega r}\right]
\end{gathered}
$$

where $\alpha$ is the angle of attack, and $\beta$ is the pitch angle.

Two forces that act on the blade element are the lifting and resisting forces [7]:

$$
\begin{aligned}
& d F_{L}=\frac{1}{2} \rho c V_{r e l}^{2} C_{l} d r \\
& d F_{D}=\frac{1}{2} \rho c V_{r e l}^{2} C_{d} d r
\end{aligned}
$$

where $c$ is the blade element's chord length, $C_{l}$ is the lift coefficient, and $C_{d}$ is the resistance coefficient. These coefficients change with the angle of attack $(\alpha)$ and Reynolds number $\left(R_{e}\right)$ and can be determined and chosen according to the airfoil profile.

Hence, using blade element theory, the thrust $d F$, torque $d T$, and power $d P$ can be represented as follows:

$$
\begin{gathered}
d F=\frac{1}{2} B \rho c V_{r e l}^{2}\left(C_{l} \cos \phi+C_{d} \sin \phi\right) d r \\
d T=\frac{1}{2} B \rho c V_{r e l}^{2}\left(C_{l} \sin \phi-C_{d} \cos \phi\right) r d r \\
d P=\frac{1}{2} B \rho c V_{r e l}^{2} \Omega\left(C_{l} \sin \phi-C_{d} \cos \phi\right) r d r
\end{gathered}
$$

\subsection{The Geometric Design of the Blade Shape}

Good design of the blade shape is the foundation for a tidal current turbine with the maximum water energy use coefficient and good economic benefits. The blade's shape design includes the diameter design $D$, blade quantity design $B$, blade solidity design $\sigma$, blade element chord length design $c$, and pitch angle design $\beta$. Glauert and Wilson's wind turbine design theory is commonly used. Practice has proven that wind turbine theory is feasible when applied to a water turbine. Wilson, moreover, improved Glanert's method, increased the calculation accuracy, and took more factors into consideration, so this article adopts Wilson theory for its blade shape design theory. 


\subsubsection{The Blade Design Flow Velocity}

The following method is used to calculate the design flow velocity:

$$
\overline{V_{r}}=\frac{\sum_{i=1}^{n} V_{r}(i)}{n}
$$

where $n$ is the tidal current cycle of the experimental site, $n=15$, and $V_{r}(i)$ is the rated flow velocity for a day, so the design flow velocity of the blade can be calculated via Equation (3) and $\overline{V_{r}}=1.6 \mathrm{~m} / \mathrm{s}$.

\subsubsection{The Solidity of the Blade}

The solidity of the blade $\sigma$ is a ratio between the blade's rotation plane projection area and the blade's sweep area.

These two energy capture devices have different solidity, as shown in Figures 3 and 4. It is relevant to the working area of the blade and the tip velocity ratio in the blade design:

$$
\sigma=\frac{\int_{0}^{R} B C_{r} d r}{\pi R^{2}}
$$

where $B$ is the blade quantities, $C_{r}$ is the blade element chord length at radius $r$, and $R$ is the blade radius. A portion of the blade's compactness can be represented as follows:

$$
d \sigma=\frac{B C_{r}}{2 \pi r} d r
$$

Simultaneously, Equations (4), (10), and (14) are solved as:

$$
\sigma=\int_{0}^{R} \frac{F 4 a \sin \phi^{2}}{(1-a)\left(C_{l} \cos \phi+C_{d} \sin \phi\right)} d r
$$

After obtaining the axial-induced factor, the blade's compactness can be calculated.

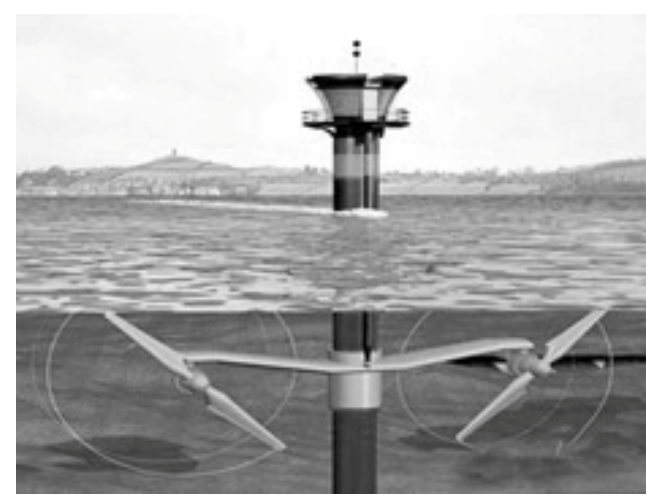

Figure 3. Turbine of the Marine Current Turbines Ltd. 


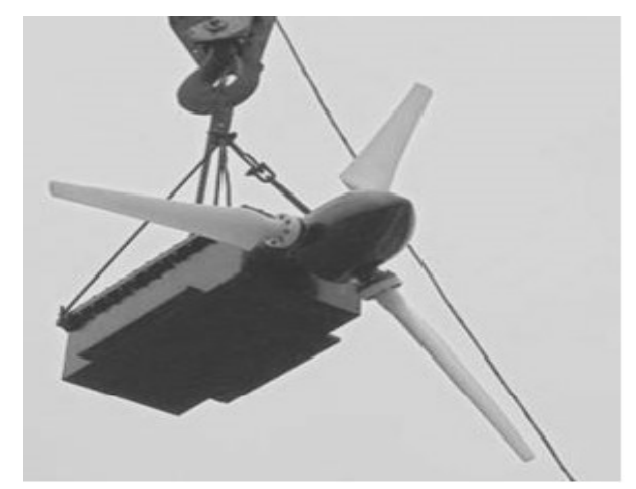

Figure 4. Turbine of Zhejiang University.

\subsubsection{Blade Quantities (BQ) and Tip-Speed Ratio (TSR)}

The $\mathrm{BQ}$ is decided by the TSR. Here, TSR is chosen as 3.6. Hence, according to Table 1, the BQ is 3 [8].

Table 1. Tip-speed ratio (TSR) and blade quantities (BQ).

\begin{tabular}{cccc}
\hline TSR & BQ & TSR & BQ \\
\hline 1 & $8 \sim 24$ & 4 & $3 \sim 5$ \\
2 & $6 \sim 12$ & $5 \sim 8$ & $2 \sim 4$ \\
3 & $3 \sim 8$ & $9 \sim 15$ & $2 \sim 3$ \\
\hline
\end{tabular}

\subsubsection{Diameter of the Blade}

The formulas for estimating the blade diameter [9] are as follows:

$$
D=\sqrt{\frac{8 P}{\rho V^{3} \pi C_{p} \eta_{1} \eta_{2}}}
$$

where $D(m)$ is the diameter of the blade, $P(w)$ is the blade design output power, $\rho\left(\mathrm{kg} / \mathrm{m}^{3}\right)$ is the density of the seawater, $v(\mathrm{~m} / \mathrm{s})$ is the seawater velocity, $C_{p}$ is the power-capture coefficient (commonly $0.35 \sim 0.45), \eta_{1}$ is the transmission system efficiency, and $\eta_{2}$ is the generator efficiency.

\subsubsection{Profile of the Blade}

The profile is extremely important for a blade and there should be a large lift-to-drag ratio at a wide range of attack angles, as well as a good lift-to-drag feature when working under the actual Reynolds number situations. Moreover, its shape should be easy to manufacture. Here, the author chose the FX77-W-XXX series profile [10], whose blade shape is as good as its performance, after analyzing multiple airfoil profiles using the Profile [11] software.

\subsection{Blade Geometric Parameter Calculations}

The overall design parameters of the blade are shown in Table 2.

The author combines the Blade Element-Momentum Theory and Wilson method to obtain the rotor power coefficient and fixed chord length formula as follows [12]:

$$
\begin{aligned}
& d C_{p}=\frac{8}{\lambda_{0}^{2}} b(1-a) F \lambda_{0}^{3} d \lambda \\
& c=\frac{8 \pi a F(1-a F) r}{B(1-a)^{2} C_{l}} \cdot \frac{\sin \phi^{2}}{\cos \phi}
\end{aligned}
$$


At the same time, $a$ and $b$ satisfy the energy equation [10]:

$$
a(a-a F)=b(1+b) \lambda^{2}
$$

The most important performance index for blade design is the power coefficient $C_{p}$. From Equation (17), it can be seen that the only way to obtain the maximum capture coefficient is to maximize the value of $d C_{p} / d \lambda$ for each blade element. Therefore, the maximum value is taken as the optimization goal function and then used to solve the other parameters:

$$
\begin{gathered}
\min : \frac{d C_{p}}{d C_{\lambda}}=-\frac{8}{\lambda_{0}^{2}} b(1-a) F \lambda_{0}^{3} \\
\text { sub }: a(1-a F)=b(1+b) \lambda^{2} \\
F=F_{\text {tip }} * F_{h u b} \\
F_{\text {tip }}=\frac{2}{\pi}\left\{\exp \left[-\frac{(R-r) * B}{2 R \sin \phi}\right]\right\} \\
F_{\text {hub }}=\frac{2}{\pi} \arccos \left\{\exp \left[-\frac{\left(r-R_{h u b}\right) * B}{2 R_{h u b} \sin \phi}\right]\right\}
\end{gathered}
$$

The author used the nonlinear constraint optimization function in the MATLAB optimization toolbox to quickly solve $a$ and $b$. It should be noted that when $a>0.38$ [10], blade element theory is no longer applicable. Therefore, the author used the more accurate Shen [11] model to modify this theory:

$$
\begin{gathered}
a=\frac{2+Y_{1}-\sqrt{4 Y_{1}(1-F)+Y_{1}^{2}}}{2\left(1+F Y_{1}\right)} \\
b=\frac{1}{(1-a F) Y_{2} /(1-a)-1} \\
Y_{1}=4 F \sin ^{2} \phi /\left(\sigma C_{n} F_{1}\right) ; \\
Y_{2}=4 F \sin \phi \cos \phi /\left(\sigma C_{l} F_{1}\right) ; \\
C_{n}=C_{l} \cos \phi+C_{d} \sin \phi ; \\
C_{l}=C_{l} \sin \phi-C_{d} \cos \phi .
\end{gathered}
$$

The blade from the hub is divided into 20 sections, and calculations are used to solve the distribution of the chord length and pitch angle, as shown in Figure 5.

By editing the algorithm, the author can use MATLAB to calculate the spatial coordinates of 20 cross-sections and then use Pro/E parameter modeling to obtain a three-dimensional model of the blade, as shown in Figure 6.

\subsection{Blade Performance Numerical Forecast}

Blade performance prediction is a necessary part of the design and verification of energy capture devices. Based on the blade element momentum heory, this article considers the necessary parameter corrections to predict the hydrodynamic performance of the designed blades. The author predict the captured power and power coefficient of the blade when the flow velocity changes from $0.8 \mathrm{~m} / \mathrm{s}$ to $2.2 \mathrm{~m} / \mathrm{s}$, as well as the thrust and thrust coefficient received.

The author use MATLAB to iteratively calculate the $a$ and $b$ at each blade element section to obtain the chord length $\mathrm{c}$ and the inflow angle $\varphi$ and then substitute those values into Equations (10) and (12). The thrust and power of the blade can then be calculated using integrals, and the thrust coefficient 
and power coefficient can also be calculated. The result is shown in Figure 7a, where the power of the blade increases with an increase of the flow rate. At a rated flow rate of $1.6 \mathrm{~m} / \mathrm{s}$, the output rated power is about $7.9 \mathrm{~kW}$, and the flow rate continues to increase. Because the blade is at a fixed pitch and adopts a passive stall control, the lift decreases. The thrust then increases, and the blade rotor speed slows. When reaching the cut-out flow rate of $2.2 \mathrm{~m} / \mathrm{s}$, the blade's capture power decreases. As shown in Figure $7 \mathrm{a}$, the blade power coefficient remains at about 0.34 before the stall. Due to the adoption of load matching variable speed operation control, the blade TSR is kept constant by controlling the blade speed before the stall to ensure maximum energy harvesting coefficient of the blade. As shown in Figure $7 \mathrm{~b}$, the thrust of the blade at the maximum flow velocity is $21 \mathrm{kN}$, which is the designed thrust of the blade mounting frame. It can also be seen in Figure $7 \mathrm{~b}$ that the thrust coefficient of the blade increases greatly when it is stalled.

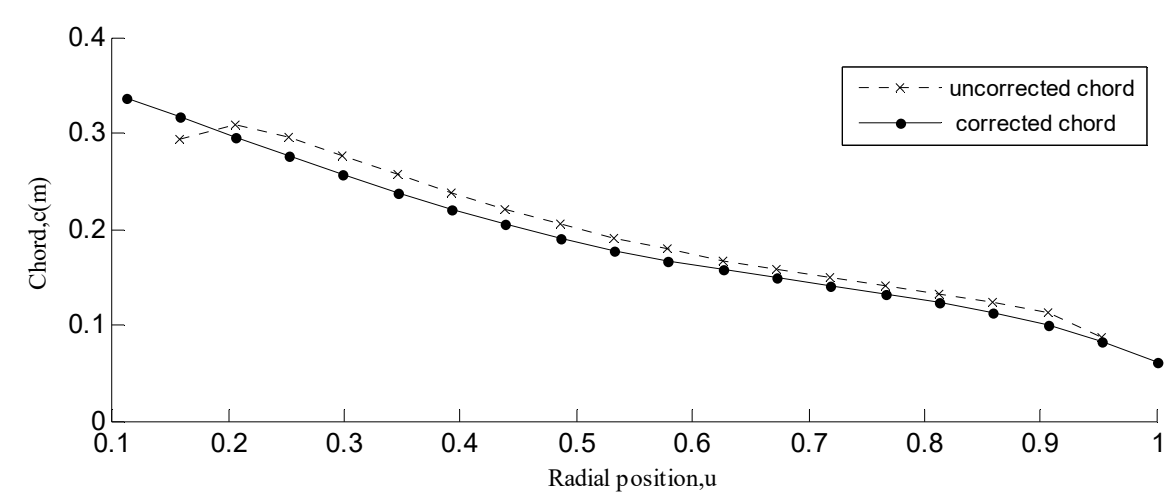

(a)

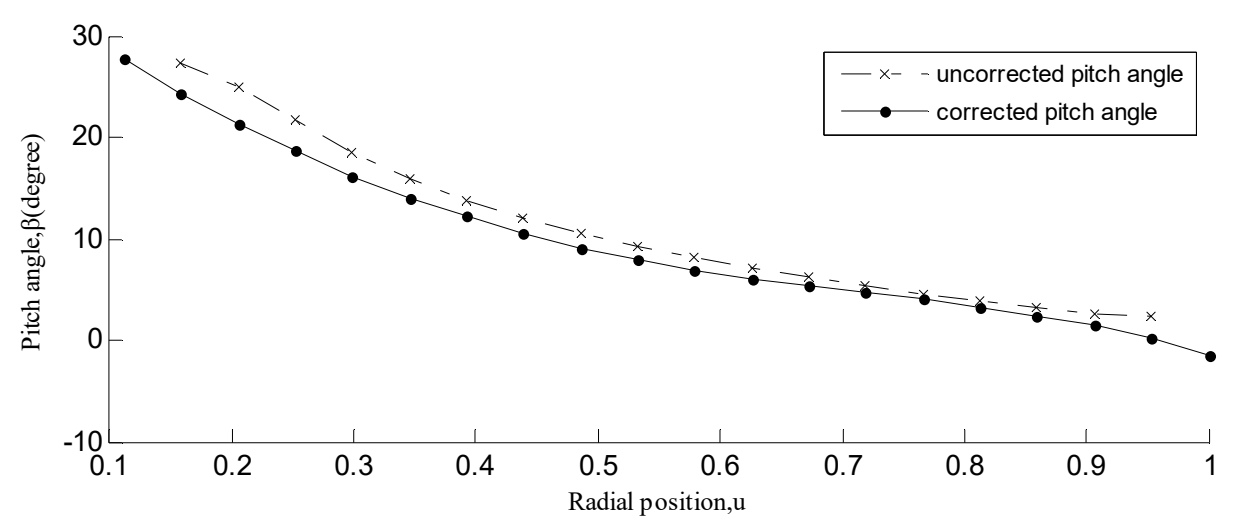

(b)

Figure 5. The geometry parameters of the blade; (a) chord length distribution, and (b) pitch angle distribution.

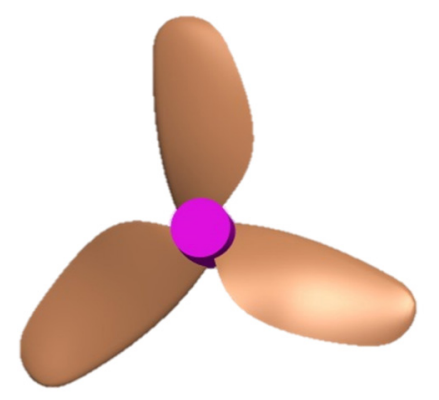

Figure 6. Three-dimensional model of the blade. 
Table 2. The overall design parameters of the blade.

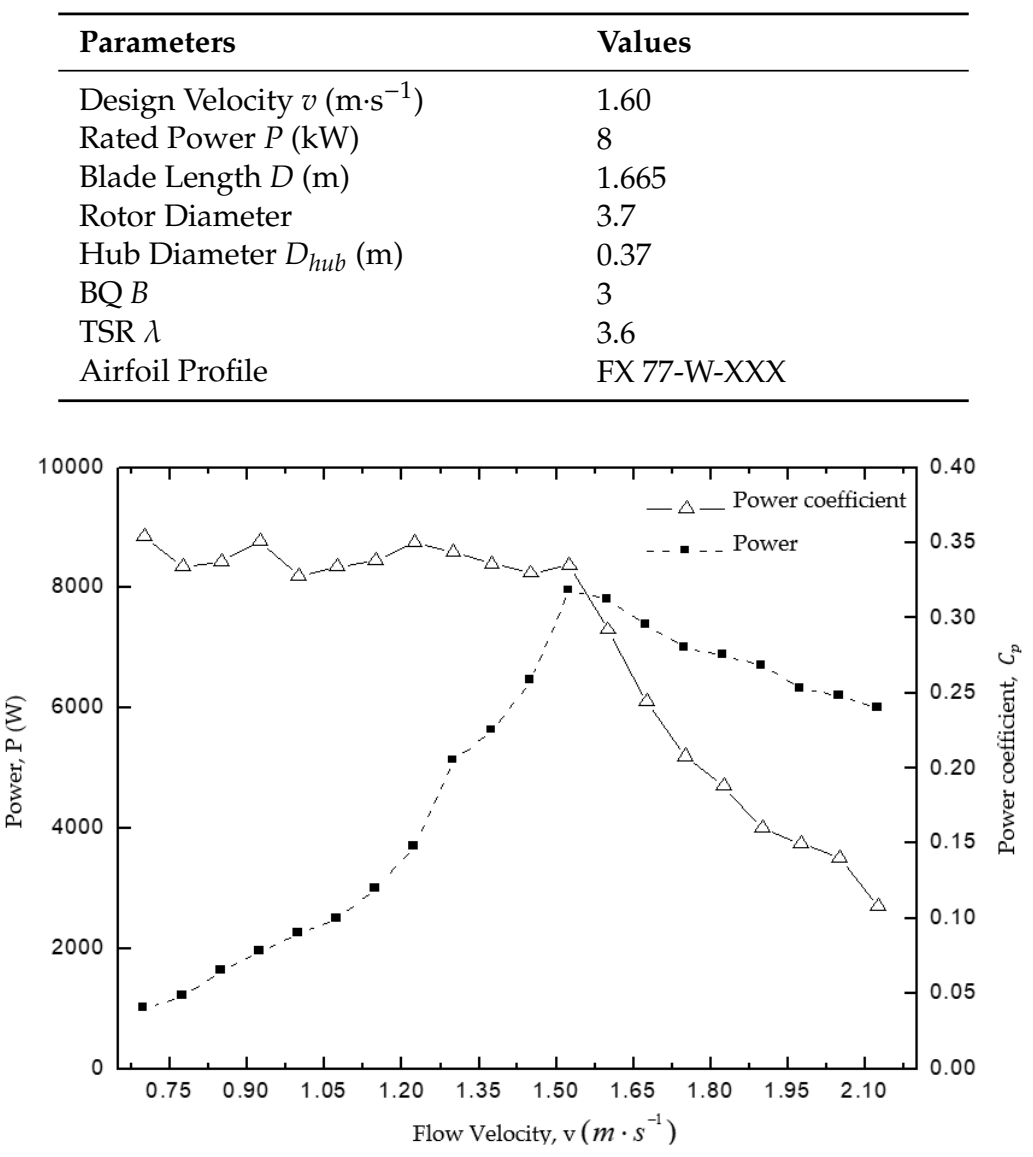

(a)

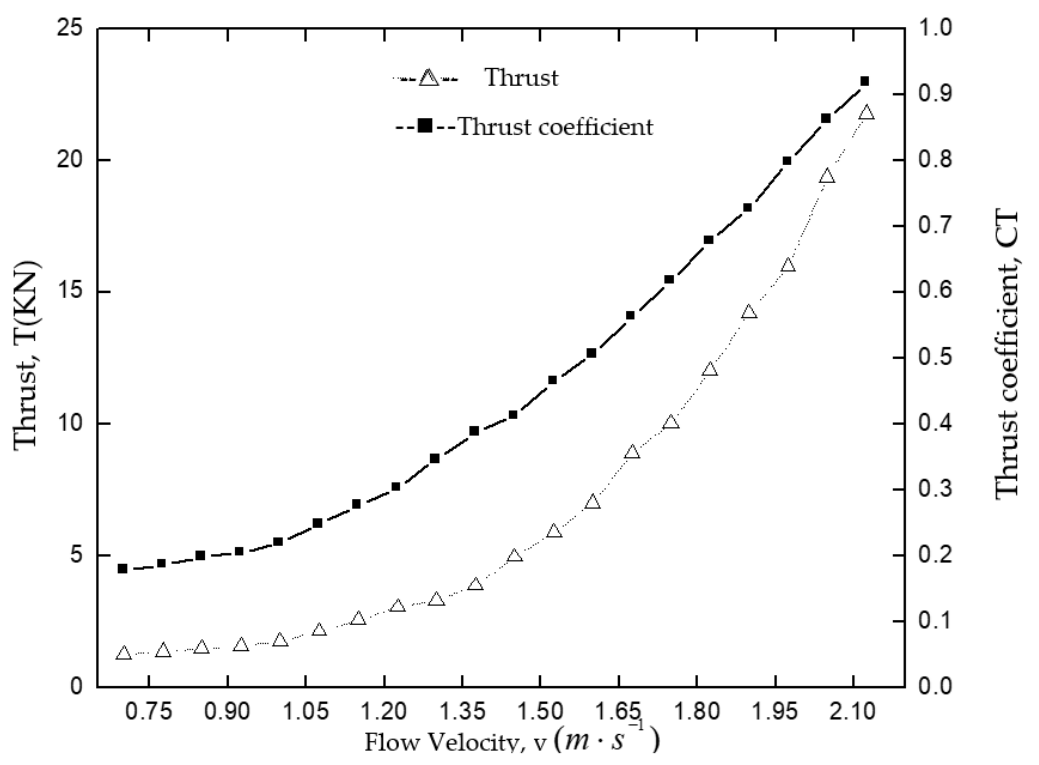

(b)

Figure 7. Performance prediction of the blade under different velocities; (a) power curve and power coefficient curve at different velocities, and (b) thrust curve and thrust coefficient at different velocities. 


\section{Experiment with an Energy Capturing Device in a Sea Trial}

A test of the tidal current power generation device was carried out on the ocean energy test platform, as shown in Figure 8. The test platform adopted the catamaran model, which features strong wind and wave stability and also facilitates the installation and maintenance of therotor. The platform was 14-m long, 10-m wide, and 6-m high, as shown in Figure 9. The tidal current power generation device is composed of a rotor, speed-increasing gears, a hydraulic transmission system, a three-phase permanent magnet synchronous generator, and an electrical control system. The rotor adopts the form of three blades and is composed of blades and a hub. The blades are made of glass-fiber-reinforced plastics, which are high-strength, lightweight, and resistant to aging. The hub is made of high-strength ductile iron, which has good mechanical properties, allows for easy formation, and can be obtained at a low cost. Figure 9 illustrates the installation site of the rotor. The speed ratio of the speed increasing gear is $25: 1$. The hydraulic transmission system consists of a variable pump and a hydraulic motor. The generator uses a rated speed of $600 \mathrm{r} / \mathrm{min}$ and three-phase four-wire permanent magnet synchronous power generation. The electrical system is composed of rectifiers, inverters, battery packs, etc. A Siemens PLC is employed as the main control system, using the Siemens AD conversion module to convert the three-phase power acquisition card, hydraulic pump pressure, flow sensor, and other analog signals into digital signals. The monitoring control system was written by LABVIEW and communicates with the Siemens PLC through the TCP protocol. The various parameters during operation can be visually displayed and recorded.

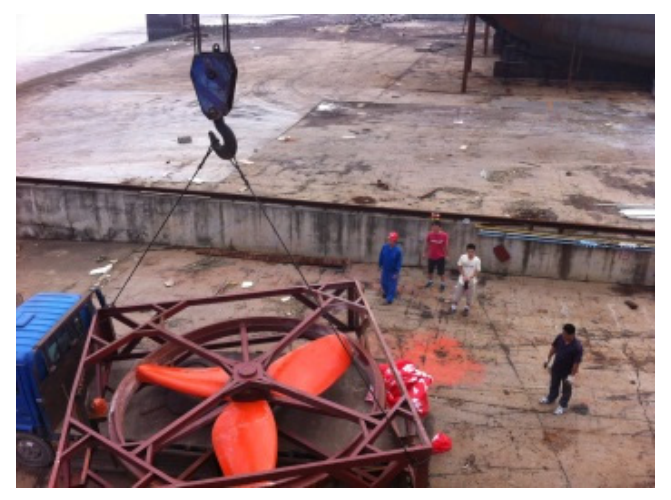

Figure 8. Rotor installation.

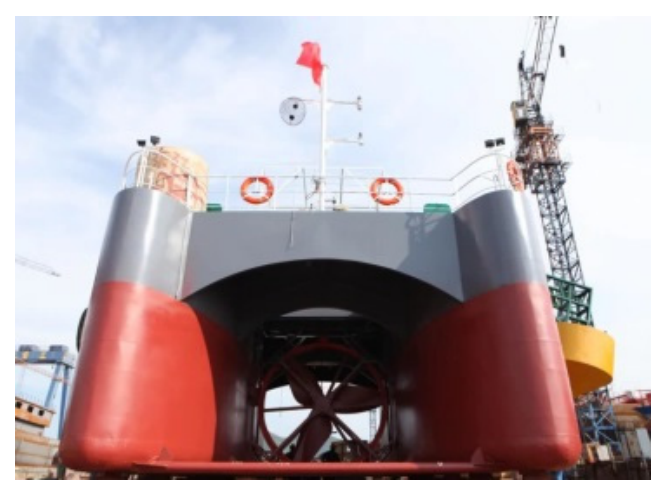

Figure 9. Marine experimental platform.

The energy harvesting device drives the hydraulic pump to rotate through the gearbox, thereby increasing the speed at which it converts tidal current energy into hydraulic energy. After the accumulator is stabilized, it drives the hydraulic motor, which then drives the generator to generate electricity and converts the hydraulic energy into electrical energy. When the rotor is working between the cut-in flow rate and the rated flow rate, the rotation speed of the blade can be changed by varying 
the displacement of the hydraulic pump to produce a reaction torque that acts on the blade to ensure maximum power capture.

During the sea experiment, the author recorded the experimental data and assessed the different blade shapes according to the energy capture device power coefficient and rotary speed of the propeller blade, as shown in Figure 10.

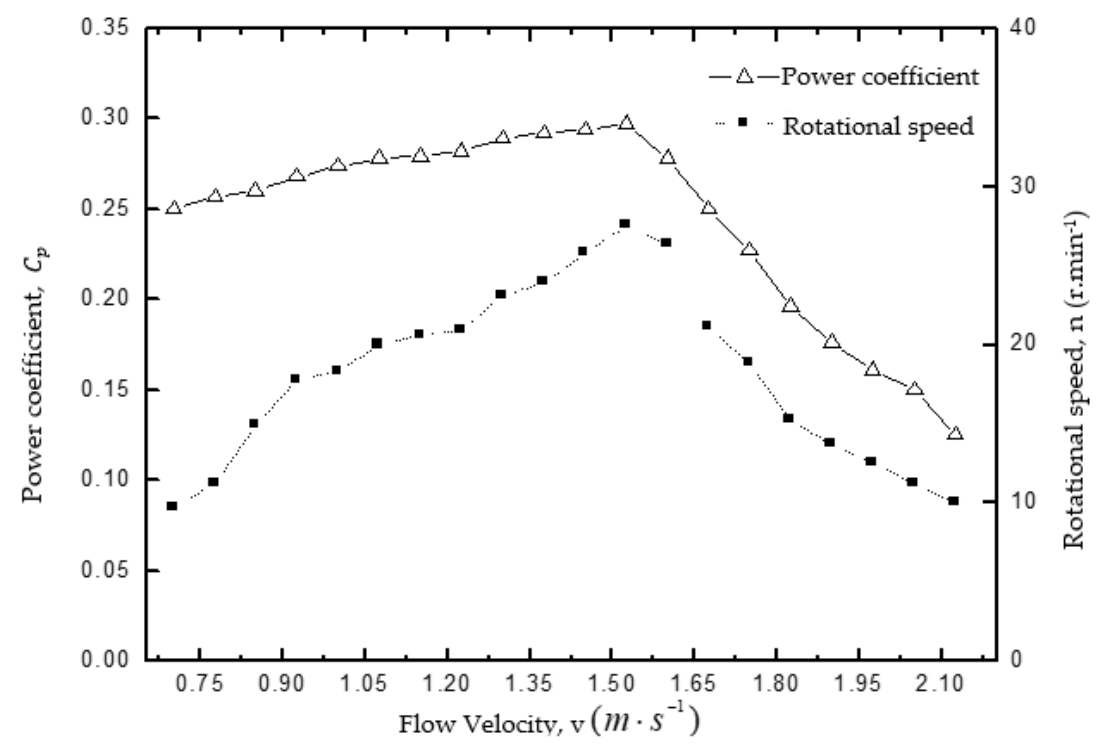

Figure 10. Performance of the blade under different velocities.

Based on the relationship between the power coefficient of the blade and the rotational speed at different flow velocities, as shown in Figure 10, the power coefficient of the blade gradually increases with an increase in the flow rate, reaching its maximum of 0.31 near the designed flow rate point. The blade then begins to stall, the power coefficient drops, and the speed decreases. In general, the experimental test data are lower than the theoretical prediction data, because, when the flow rate is reduced, to maintain the best TSR, the displacement of the variable pump must be changed to apply counter torque to the blades. As a result, the pump pressure changes, and the pump efficiency is reduced, which increases the difficulty in load matching and causes the power generation coefficient to be lower than the predicted value.

Based on the comparison of the power coefficient between prediction data and experimental data under different flow velocity, as shown in Figure 11, the experimental test data are lower than the theoretical prediction data. The reasons may be the following two points:

1. Considering the measurement, the flow velocity tested in the experiment is relatively close to the surface flow velocity, so it is higher than the actual flow velocity at the center of the blade, which will lead to the calculated experiment data are lower.

2. The theoretical prediction model cannot fully consider the actual sea conditions at the trial experimental site, which may also cause deviations between experimental data and theoretical data.

Therefore, to improve the accuracy of theoretical predictions, it is necessary to make further corrections and improvements based on experimental data. 


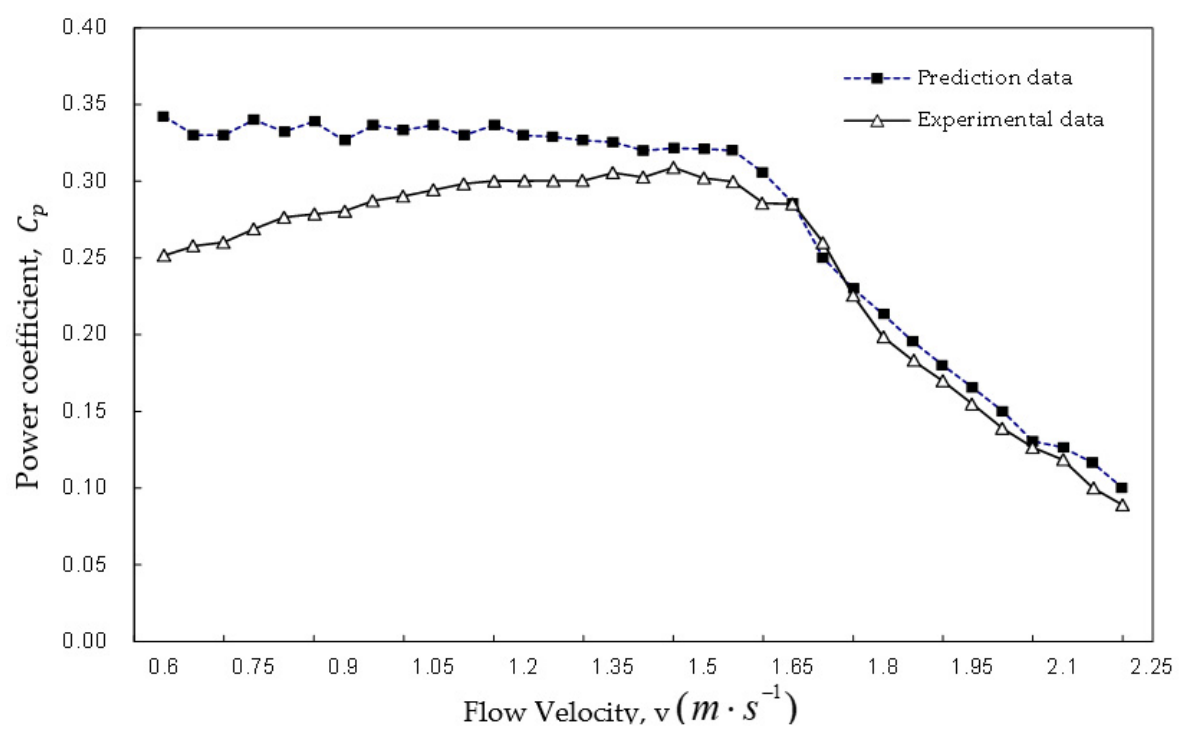

Figure 11. Comparison of prediction and experimental data.

\section{Conclusions}

(1) During the 1.5-month period at the test site, the maximum flow rate of the seawater per day was different and maintained for a short period of time. Flow rates above $2 \mathrm{~m} / \mathrm{s}$ only appeared on astronomical high-tide days, but were low the majority of the time. Based on this situation, the author proposed a calculation method for designing the flow velocity of the blade to improve the energy capture efficiency of the blade within the range of the changing flow velocity.

(2) The author combined the blade element momentum theory with the Wilson optimization method and used the MATLAB software to compile a general program for the design of an energy capture mechanism for the horizontal-axis tidal current power generation system, to improve the design efficiency and accuracy.

(3) The author deduced the relationship between the solidity of the blade and the TSR. For the design of the blade, when the design flow rate is constant, the appropriate blade solidity can be selected according to the blade speed.

(4) Based on the actual sea experiment, the energy capture device met the basic design requirements, which verifies the effectiveness and correctness of this blade design method.

Author Contributions: Conceptualization, J.-H.C. and H.L.; methodology, H.L.; validation, H.L. and X.-C.W.; formal analysis, H.L.; investigation, L.-J.B. and C.-H.J.; writing-original draft preparation, H.L.; writing-review and editing, H.L. All authors have read and agreed to the published version of the manuscript.

Funding: This research received no external funding.

Acknowledgments: The authors wish to thank reviewers who gave valuable suggestion that has helped to improve the quality of the manuscript. The authors also would like to thank editors for the paper revisions and language editing.

Conflicts of Interest: The authors declare no conflict of interest.

\section{References}

1. Xu, X.T. The Design and Characteristics Analysis on the Blade of Horizontal Axis Tidal Current Turbine. Master's Thesis, Zhejiang University, Hangzhou, China, 2012. Available online: http://cdmd.cnki.com.cn/ Article/CDMD-10335-1012321157.htm (accessed on 18 November 2020).

2. Li, Y.W. The Development on Marine Energy; China Ocean Press: Beijing, China, 2008; pp. 94-101.

3. Pratumnopharat, P.; Leung, P.S. Validation of various Windmill brake state models used by blade element momentum calculation. Renew. Energy 2011, 36, 3222-3227. [CrossRef] 
4. Xu, Q.-K.; Li, W.; Liu, H.W.; Lin, Y.-G.; Shi, M.-S. Individual blade pitching system for horizontal axis tidal current turbine. J. Zhejiang Univ. Eng. Sci. 2013, 47, 528-534.

5. Grogan, D.M.; Leen, S.B.; Kennedy, C.R.; Bradaigh, C.O. Design of composite tidal turbine blades. Renew. Energy 2013, 57, 151-162. [CrossRef]

6. Chen, C.F. Optimization and Hydrodynamic Performance Research on the Blade of Horizontal Axis Tidal Current Turbine. Master's Thesis, Ocean University of China, Qingdao, China, June 2012.

7. Wu, H.N.; Chen, L.J.; Yu, M.; Li, W.; Chen, B. On design and performance prediction of the horizontal-axis water turbine. Ocean. Eng. 2012, 50, 23-30. [CrossRef]

8. Goundar, J.N.; Ahmed, M.R.; Lee, Y.H. Numerical and experimental studies on hydrofoils for marine current turbines. Renew. Energy 2012, 42, 173-179. [CrossRef]

9. Li, G.N.; Yang, Z.F.; Du, B.S.; Xu, J.J.; Liu, M. The design and modeling on the wind turbine rotor based on MATLAB and Pro/E. Mech. Des. 2009, 26, 3-5.

10. Ma, S.; Li, W.; Liu, H.W.; Lin, Y.G. The design on energy capture institution of horizontal axis tidal current turbine. Chin. J. Mech. Eng. 2010, 46, 150-157.

11. Chen, Q.H.; Lai, H. The analysis on different tip loss model of wind turbine aerodynamic performance. Acta Energ. Sol. Sin. 2012, 33, 216-2171.

12. Balaka, R.; Rachman, A. Pitch angle effect for horizontal axis river current turbine. Procedia Eng. 2012, 50, $343-353$.

Publisher's Note: MDPI stays neutral with regard to jurisdictional claims in published maps and institutional affiliations. 